\title{
Pandemic of Fear or what Statistics Hide: Patients with Cardiovascular Disease are at Increased Risk During COVID-19
}

\author{
Oleg V. Gaisenok ${ }^{1}$
}

1. Research Center of Medical Forecasting and Analysis, Moscow, Russia

2. United Hospital with Outpatient Department, Moscow, Russia

\author{
Corresponding author: \\ Oleg V. Gaisenok \\ Department of Cardiology and Internal diseases, \\ United Hospital with Outpatient Department, \\ Michurinsky Avenue 6, Moscow, Russia, 119285 \\ E-mail: ovg.07@bk.ru
}

\section{Highlights}

Insufficien statistical information on the structure of mortality in the era of the pandemic is disclosed in this article. It analyzes the statistics and the causes of death during the COVID-19 pandemic from a new coronavirus infection and cardiovascular disease. Actual international data on a decrease in the hospitalization rate of patients with acute coronary syndrome are presented. A comparative analysis of statistics from European countries and Russia shows that cardiovascular diseases are the leading cause of death in populations, and patients with cardiovascular diseases are at increased risk for morbidity and mortality during the COVID pandemic.

Keywords: COVID-19; pandemic; statistics; cardiovascular diseases; mortality

Citation: $\quad$ Gaisenok O. Pandemic of Fear or what Statistics Hide: Patients with Cardiovascular Disease are at Increased Risk During COVID-19. . International Cardiovascular Forum Journal 2020;21:2-6.DOI: 10.17987/icfj.v21i0.711. Accepted 4/10/20.

\section{Introduction}

The pandemic of fear that swept the world in the midst of the spread of a new coronavirus infection, actively fueled by the media, has led to major changes in society, the transformation of previously accepted attitudes to behavior, communication, analysis of available information. It also touched on the issues of obtaining medical care, in the wider and more accessible volume that was possible before the COVID-19 pandemic. All together, this has led to the fact that the adoption of the term "psychopharmacology" and the rational use of psychotropic drugs and antidepressants in patients during a pandemic has become an urgent issue on the agenda today [1]. The panic of the population led to the fact that all antiviral and antiinflammatory drugs were sold out in pharmacies, and the price of medical masks and gloves increased at times.

The largest pharmaceutical companies have the opportunity to increase their income by selling drugs on the medical market significantly higher than the cost of their production [2]. Drugs that were previously used in the treatment of AIDS, Ebola hemorrhagic fever, malaria (lopinavir / ritonavir, remdesivir, chloroquine / hydroxychloroquine) began to be used actively off-label, although they did not have proven effectiveness in the treatment of COVID-19 [3-5]. At the same time, many of them had serious side effects and drug interactions that made the medical community question their appropriateness [6].

It became known that a new coronavirus infection has a more severe course in people over 65 suffering from concomitant diseases, especially in polymorbid patients. Such patients were more often hospitalized in the intensive care unit (ICU). Of those hospitalized in ICUs, the proportion of which from all infected was up to $20.3 \%$, severe acute respiratory distress syndrome developed in $32.8 \%$ [7]. The mortality rate among patients hospitalized in this category of patients is quite high [7], due to the fact that the main critical complications are acute respiratory failure, pulmonary embolism and DIC $[8,9]$. It is worth noting that patients with concomitant cardiovascular diseases, including those suffering from arterial hypertension, are at increased risk of developing severe complications when infected with COVID-19 [10].

Evidence has been obtained that a viral infection provokes active diffuse inflammation of the vascular endothelium, which 
leads to a violation of the microcirculation of the vascular bed, the risk of thrombosis and requires additional supportive therapy [11]. On the one hand, we need to understand that the data of epidemiology and statistics are rapidly changing and updated, they need to be correctly interpreted, and the "sample" indicated in the studies should be correctly evaluated. In this case, it is necessary to compare morbidity and mortality with other categories of diseases and compare them according to the age ranges of sick / dead (which the media around the world categorically did not do, escalating the pandemic of fear regarding COVID-19).

On the other hand, one must understand the serious role of cardiovascular diseases and their contribution to the overall mortality rate: more than 4 million deaths occur in Europe annually, in other words, on average 11 thousand Europeans die every day from CVD (1 death every 8 seconds) [12]. In this regard, if we turn to statistics using available Internet resources, we can estimate and compare morbidity and mortality in European countries from COVID-19 [13,14] (Table 1).

Of great interest to the medical community will be the widespread publication in the future of statistical data from around the world on mortality rates from diffe ent groups of diseases in comparison with COVID-19 during this pandemic. Particular attention in this matter will be given to countries such as Sweden and Belarus, which have refused quarantine measures and a strict regime of self-isolation for their citizens. If the current data from these countries on the number of COVID-19 infected are relatively comparable (Sweden, $\mathrm{n}=$ 71419; Belarus, $n=68125)$; then the mortality data from this disease are very diffe ent (Sweden, $n=5420,7.6 \%$; Belarus, $n=423,0.7 \%$ ). If we compare these indicators at this date with countries such as Russia and the USA, the data will be completely diffe ent: Russia (the number of infected $n=681251$, the number of deaths $n=10161,1.5 \%$ ); USA (number of infected $\mathrm{n}=2936904$, number of deaths $\mathrm{n}=132335,4.5 \%$ ) [13,14]. Of course, this may be due to the peculiarities of accounting for cases of diseases and coding of causes of death on the basis of the ICD-10 classifier for both these and other countries of the world to which similar questions arose.

The widespread problem of patient polymorbidity does not allow one code in some cases to reflect all competing diseases in a patient on the one hand, and on the other hand, it is probably necessary to understand the diffe ences between the concepts of infected and diseased.

A higher count of infected people is unambiguously observed in countries where testing of the population with PCR for SARSCOV-2 was more actively and widely conducted. Data on a certain percentage of false-negative and false-positive results of these analyzes led to the fact that in a number of countries the diagnosis was made only by the picture characteristic of COVID-19 pneumonia during chest computed tomography, without confirmation by the PCR method

It became known that the Russian Ministry of Health will send proposals to $\mathrm{WHO}$ on improving the application of the International Methodological Recommendations for the refinement and coding of COVID-19 as a cause of death. The

\section{Table 1. 10 European countries leading in the percentage mortality rate from all officially registered cases of infected people (as on 03.07.2020).}

\begin{tabular}{|l|l|l|l|l|}
\hline & Country & Death percent & Deaths & Infected \\
\hline 1 & France & $15,8 \%$ & 29893 & 189220 \\
\hline 2 & Belgium & $15,8 \%$ & 9771 & 61838 \\
\hline 3 & Italy & $14,4 \%$ & 34854 & 241419 \\
\hline 4 & UK & $14,1 \%$ & 44198 & 313483 \\
\hline 5 & Hungary & $14,1 \%$ & 589 & 4183 \\
\hline 6 & Netherlands & $12,1 \%$ & 6113 & 50335 \\
\hline 7 & Spain & $9,5 \%$ & 28385 & 297625 \\
\hline 8 & Sweden & $7,6 \%$ & 5420 & 71419 \\
\hline 9 & Ireland & $6,8 \%$ & 1741 & 25509 \\
\hline 10 & Slovenia & $6,5 \%$ & 111 & 1700 \\
\hline
\end{tabular}

ministry claims that the postmortem examination of the bodies of $98 \%$ of the dead from COVID-19 in Russia allows to assess the true impact of the new coronavirus infection on mortality [15]. A similar situation is in Germany, as some recent publications confirm [16,17]. A postmortem examination of those who died from SARS with confirmed SARS-CoV-2 infection can provide important information about the course of this new disease, and is necessary for the correct statistical registration of deaths from COVID-19. In the northern federal district of Hamburg, all deaths with PCR-confirmed SARS-CoV-2 infection before or after death have been autopsy since the pandemic in Germany [17].

The Ministry of Health of Russia approved the Guidelines for coding and selection of the main condition in the statistics of morbidity and the initial cause in the statistics of mortality associated with COVID-19. The document clearly reflect recommendations for the preparation of primary medical documentation for patients with coronavirus infection, for reporting cases associated with COVID-19 in morbidity and mortality statistics, as well as examples in which it is proposed that coronavirus infection be considered the initial cause of death [18]. The recommendations are based on the principles established by the International Classification of Diseases of the World Health Organization (ICD-10), taking into account the International Guidelines for the identification and coding of COVID-19 as the cause of death. The proposed approaches to coding and selection of the ground state in morbidity statistics and the initial cause in mortality statistics are based on an in-depth study of the course of a new coronavirus infection and its effect on the body. This will allow you to get the most relevant, objective and detailed statistics on this disease and more widely assess the impact of infection on humans and the course of the disease.

SaRS-COV-2 has a tendency to affect patients with chronic diseases and especially older people (which increases mortality in this category of patients). The concentration of these patients in some hospitals, which were reprofiled and whose staff, as a rule, were not previously experienced in treating patients with severe pneumonia, respiratory distress syndrome, and similar conditions, significantly "worsened" the mortality statistics. An 
increase of mortality from severe cases and complications of COVID-19 is observed in older age groups, which is confirme by data published by Italian researchers. Thus, when comparing mortality rates for three countries, the following results were obtained: South Korea $-1.4 \%$ for the age range of $60-69$ years, $5.3 \%$ for $70-79$ years, $9.3 \%$ for people over 80 ; China $-3.6 \%$ for the age range of $60-69$ years, $8.0 \%$ for $70-79$ years old, $14.8 \%$ for people over 80 years old; Italy $-3.5 \%$ for the age range of $60-69$ years, $12.5 \%$ for $70-79$ years, $20.2 \%$ for people over 80 [19].

But it can be assumed that mortality from this pathology is overestimated - the presence of PCR should not determine the causality of mortality of these patients - when there are other diseases that are the rationale for fatal outcome. Economically advantageous tariffs for providing COVID care to patients and pathological studies could theoretically cause data bias when taking into account cases of morbidity and mortality. But it is worth noting that, population mortality from COVID-19 corresponds to population mortality according to the age of over 65 years. A case in point is the analysis of morbidity and mortality data in a closed collective such as the Diamond Princess cruise ship. On February 26, cases of infection based on a positive PCR test were confirmed in 705 of 4,061 passengers [20]. Over the entire period of quarantine on the ship, only 7 people died -3 at the age of $70-79$ years and 4 at the age of $80-89$ years. $17.4 \%$ of passengers were infected with the virus; mortality from the total number of ship passengers and infected was respectively $0.17 \%$ and $0.9 \%$ [21].

In addition, it is worth noting that according to some data, the death rate from influenza during the period of exceeding the epidemic threshold exceeds the death rate from COVID-19 [22]. Regarding the problem of increasing mortality from cardiovascular diseases during a pandemic, can assume its growth worldwide. During the peak of the epidemic of coronavirus infection in Moscow hospitals, the number of patients with acute coronary syndrome sharply decreased - in April 2020 compared to April 2019 by 43\%. This was announced on May 26, 2020 by the director of the Scientifi and Research Center of Cardiology, the chief cardiologist of the Ministry of Health Sergey Boytsov in the framework of the "Orgzdrav 2020" congress [23]. The number of hospitalizations of patients with non-STEMI has decreased over this period in Moscow by $46 \%$, in the Moscow region by $60 \%$, in the Bryansk region by $86 \%$. There is also information about a sharp increase in the time before sending an emergency call due to a sharp increase in workload and a lack of medical teams. It is worth noting the likely contribution to the formation of this trend that patients refuse hospitalization (due to fear of COVID-19) and the reprofiling of medical facilities. Academician of the RAS Sergey Boytsov noted that the mortality rate in all federal districts greatly exceeded the targets of the national project for 2020. Probably these sad statistics on the increase in total mortality during the pandemic (primarily due to cardiovascular mortality) were the reason for the sudden and unexpected cancellation of quarantine measures by the Moscow government - while the number of registered cases of newly infected in the city remained the same level (about 8 thousand).

A similar situation with the provision of medical care to patients with cardiovascular diseases is observed in other countries, in particular in Europe. Representatives of the Italian Society of Cardiology conducted a multicenter observational nationwide study to collect data on admission of patients with acute myocardial infarction (AMI) to Italian clinics for 1 week during the outbreak of COVID-19 compared to the same week in 2019 [24]. There was a decrease in the number of hospitalizations for AMI by $48.4 \%$ compared with the same week in 2019 ( $p$ $<0.001)$. The decrease was significant for STEMI $(26.5 \%, 95 \%$ confidence interval 21.7-32.3; $\mathrm{p}=0.009$ ) and for non-STEMI (65.1\%, 95\% confidence interval 60.3-70.3; $\mathrm{p}<0.001)$. Mortality from STEMI during the pandemic was significantly higher compared to 2019 (risk ratio $(R R)=3.3,95 \%$ confidence interval $1.7-6.6 ; p<0.001)$. An increase in the number of complications of the disease was recorded $(R R=1.8,95 \%$ confidence interval $1.1-2.8 ; p=0.009)$. At the conclusion of their study, the authors noted that hospitalization of patients with AMI was significantl reduced during the COVID-19 pandemic in all regions of Italy, with a parallel increase in the number of deaths and complications. This is a serious social problem that requires close attention from the scientific and medical community and state regulatory institutions [24].

This trend is confirmed by the data of an online survey conducted by the European Society of Cardiology among members of the society regarding the analysis of the hospitalization of patients with STEMI during the COVID-19 pandemic. The survey involved 3101 respondents from 141 countries on six continents $(58 \%$ of the respondents were from Europe $(n=$ 1800); $23.7 \%$ from Asia $(n=734)$ ). The survey showed that one of the main consequences of the pandemic was a sharp reduction in hospitalization of patients with ACS, and this phenomenon has affected many hospitals around the world. $78.8 \%$ of respondents confirmed the fact that the number of patients with STEMI entering their hospitals decreased by an average of $50 \%$. Many medical professionals also noted that patients with STEMI who were hospitalized in hospitals had a significant delay in hospitalization, and $62.3 \%$ of respondents said that patients with STEMI were hospitalized later than the prescribed time before $\mathrm{PCl} /$ thrombolysis. The percentage of patients who arrived later than usual averaged $48 \%$. Up to $68 \%$ of respondents said that the cardiology department was "partially" or "completely" reorganized to accommodate infected patients [25].

Probably one of the reasons for this was the fact that for several months people with chronic diseases were forced to observe safety measures and were at home in a "self-isolation regime". This inevitably led to a limitation of social contacts (which led to the formation of feelings of loneliness, depression), which was aggravated by the constant flow of frightening information from the media (which contributed to the formation of anxiety disorder). Changes in the system of medical care resulted in the inability to plan a scheduled visit to a doctor and in-person medical consultations. The lack of physical activity for several months inevitably should lead to an increase in body weight. Overweight / obesity not only increases the risk of developing cardiovascular diseases and their complications [26], but is also considered a risk factor for pneumonia, its severity [27] and, according to recent data, is a factor predisposing to COVID-19 [28]. 
Ashraf S. et al. confirmed these judgments and identifie additional reasons for this in their publication [29]. It is suggested that some patients remain at home and try to treat their symptoms on their own until the restrictions on selfisolation are removed. The fact that staying at home and social distance leads to a low level of physical activity, in which the typical symptoms of angina pectoris does not develop, is considered. The authors also express the idea that patients do not go to the hospital at all even when they experience chest pain due to fear of being infected with a new coronavirus infection during their stay in the hospital. In addition, it is worth noting the important impact of COVID-19 on the economy and the formation of financial difficultie for many segments of the population (including those related to a decrease in wages or even job loss), which created another barrier to seeking medical help. There is also some degree of misinformation and lack of consensus at the national and international levels throughout the world. At the same time, the media in covering public health problems completely shifted their focus to COVID-19 and did not reflect the true statistics of mortality from other diseases, completely ignoring and not mentioning the problem of the pandemic of cardiovascular diseases. In this regard, I would like to give true statistics comparing the indicators of total mortality, mortality from cardiovascular diseases and COVID-19 between two countries: Russia and Italy, based on officia statistical information $[30,31]$ (Table 2).

\section{Conclusion}

The findings suggest a pandemic of cardiovascular disease, which has never receded. But her new wave came during the COVID-19 pandemic. All those additional factors (lack of physical activity, isolation, weight gain, stress, depression, restrictions on the availability of medical care, a decrease

\section{Table 2. Comparative analysis of indicators of total mor- tality, mortality from cardiovascular diseases and from COVID-19 in Italy and Russia.}

\begin{tabular}{|c|c|c|}
\hline Indicator & Italy & Russia \\
\hline Population & $\begin{array}{l}59500000 \\
(2016)\end{array}$ & $\begin{array}{l}146000000 \\
(2018)\end{array}$ \\
\hline Total mortality (per year) & 640000 & 1830000 \\
\hline $\begin{array}{l}\text { Mortality from circulatory system } \\
\text { diseases (per year) }\end{array}$ & $\begin{array}{l}230400 \\
(36 \%)\end{array}$ & $\begin{array}{l}856000 \\
(47 \%)\end{array}$ \\
\hline $\begin{array}{l}\text { Dies in the country in a month (from } \\
\text { all diseases) }\end{array}$ & 52590 & 150300 \\
\hline $\begin{array}{l}\text { Dies in the country in a month (from } \\
\text { circulatory system diseases) }\end{array}$ & 18930 & 70356 \\
\hline $\begin{array}{l}\text { Dies in the country in a day (from } \\
\text { all diseases) }\end{array}$ & 1753 & 5010 \\
\hline $\begin{array}{l}\text { Dies in the country in a day (from } \\
\text { circulatory system diseases) }\end{array}$ & 631 & 2345 \\
\hline $\begin{array}{l}\text { Died of COVID-19 for the entire } \\
\text { period of the pandemic (for first } 3.5 \\
\text { months) }\end{array}$ & 33601 & 10161 \\
\hline $\begin{array}{l}\text { Estimated mortality from COVID-19 } \\
\text { per month (during a pandemic) }\end{array}$ & 9600 & 2903 \\
\hline $\begin{array}{l}\text { Estimated mortality from COVID-19 } \\
\text { per day (during a pandemic) }\end{array}$ & 320 & 94 \\
\hline
\end{tabular}

in population income, etc.), the active influence of which became possible during the period of quarantine measures and self-isolation regime, certainly led to an increase total and cardiovascular mortality worldwide. All this should compel the international medical community and state governments to urgently develop measures to address these issues.

\section{Conflict of interest}

The author declares no conflicts of inte est.

\section{Acknowledgements}

The author states that he abides by the "Requirements for Ethical Publishing in Biomedical Journals" [32].

\section{References}

1. Bilbul M, Paparone P, Kim AM, et al. Psychopharmacology of COVID-19. Psychosomatics. 2020 May 18. Online ahead of print. doi: 10.1016/j. psym.2020.05.006

2. Hill A, Wang J, Levi J, et al. Minimum costs to manufacture new treatments for COVID-19. J Virus Erad. 2020 Apr 30;6(2):61-69. doi: 10.1016/S20556640(20)30018-2

3. Doggrell SA. Does lopinavir measure up in the treatment of COVID-19? Expert Opin Investig Drugs. 2020 Jun 12;1-4. Online ahead of print. doi:10. 1080/13543784.2020.1777277

4. Tchesnokov EP, Feng JY, Porter DP, et al. Mechanism of Inhibition of Ebola Virus RNA-Dependent RNA Polymerase by Remdesivir. Viruses. 2019;11(4):326. doi:10.3390/v11040326

5. Gautret $\mathrm{P}$, Lagier JC, Parola $\mathrm{P}$, et al. Hydroxychloroquine and azithromycin as a treatment of COVID-19: results of an open-label non-randomized clinical trial. Int J Antimicrob Agents. 2020 Mar 20;105949. Online ahead of print. doi: 10.1016/j.ijantimicag.2020.105949.

6. Gaisenok O.V. Drug interactions and side effects of co-administration of chloroquine / hydroxychloroquine and azithromycin: to the question of rational pharmacotherapy in patients with COVID-19 using antimalarial drugs. Rational Pharmacotherapy in Cardiology. 2020;16(3):481-486. doi: 10.20996/1819-6446-2020-06-08

7. Rodriguez-Morales AJ, Cardona-Ospina JA, Gutiérrez-Ocampo E, et al; Latin American Network of Coronavirus Disease 2019-COVID-19 Research (LANCOVID-19). Electronic address: https://www.lancovid.org. Clinical, laboratory and imaging features of COVID-19: A systematic review and meta-analysis. Travel Med Infect Dis. 2020 Mar-Apr;34:101623. doi: 10.1016/j.tmaid.2020.101623

8. Lodigiani C, lapichino G, Carenzo L, et al; Humanitas COVID-19 Task Force. Venous and arterial thromboembolic complications in COVID-19 patients admitted to an academic hospital in Milan, Italy. Thromb Res. 2020 Jul;191:9-14. doi: 10.1016/j.thromres.2020.04.024.

9. Du RH, Liang LR, Yang $C Q$, et al. Predictors of mortality for patients with COVID-19 pneumonia caused by SARS-CoV-2: a prospective cohort study. Eur Respir J. 2020 May 7;55(5):2000524. doi: 10.1183/13993003.005242020

10. Bhimraj A, Morgan RL, Shumaker AH, et al. Infectious Diseases Society of America Guidelines on the Treatment and Management of Patients with COVID-19. Clin Infect Dis. 2020 Apr 27:ciaa478. doi: 10.1093/cid/ciaa478. Epub ahead of print.

11. Varga Z, Flammer AJ, Steiger $P$, et al. Endothelial cell infection and endotheliitis in COVID-19. Lancet. 2020 May 2;395(10234):1417-1418 doi: 10.1016/S0140-6736(20)30937-5

12. European Cardiovascular Disease Statistics (2012) https://www.escardio org/The-ESC/What-we-do/Initiatives/EuroHeart/2012-EuropeanCardiovascular-Disease-Statistics-Visuals [Accessed on 03.06.2020]

13. COVID-19 Dashboard by the Center for Systems Science and Engineering (CSSE) at Johns Hopkins University https://coronavirus.jhu.edu/map.html [Accessed on 03.07.2020]

14. Global Coronavirus Statistics https://epidemic-stats.com/ [Accessed on 03.07.2020]

15. MEDVESTNIK: Russian doctor portal. Ministry of Health proposes WHO to change coding of deaths from COVID (Russian; author's translation) https:// medvestnik.ru/content/news/Minzdrav-predlojit-VOZ-izmenit-poryadokkodirovaniya-smertei-ot-COVID-19.html [Accessed on 03.06.2020]

16. Wichmann D, Sperhake JP, Lütgehetmann M, et al. Autopsy Findings and Venous Thromboembolism in Patients With COVID-19. Ann Intern Med. 2020 May 6:M20-2003. doi: 10.7326/M20-2003

17. Edler C, Schröder AS, Aepfelbacher M, et al. Dying with SARS-CoV-2 infection-an autopsy study of the first consecutive 80 cases in Hamburg, Germany. Int J Legal Med. 2020 Jun 4:1-10. doi: 10.1007/s00414-02002317-w. Epub ahead of print. 
18. Guidelines for coding and selection of the underlying state in morbidity statistics and the initial cause in mortality statistics associated with COVID-19. Moscow, 27.05.2020. - 24p. (Russian; author's translation) https://static-1.rosminzdrav.ru/system/attachments/attaches/000/050/527/ original/27052020_MR_STAT_1.pdf [Accessed on 03.06.2020]

19. Ferrari R, Maggioni AP, Tavazzi L, et al. The battle against COVID-19: mortality in Italy. Eur Heart J. 2020 Jun 7;41(22):2050-2052. doi: 10.1093/ eurheartj/ehaa326.

20. About new coronavirus infectious disease confirmed on cruise ship under quarantine at Yokohama Port (published on February 26) (Japanise; author's translation) www.mhlw.go.jp [Accessed on 03.06.2020]

21. Russell TW, Hellewell J, Jarvis $\mathrm{Cl}$, et al. Estimating the infection and case fatality ratio for coronavirus disease (COVID-19) using age-adjusted data from the outbreak on the Diamond Princess cruise ship, February 2020. Euro Surveill. 2020 Mar;25(12):2000256 doi: 10.2807/1560-7917. ES.2020.25.12.2000256

22. Fauci AS, Lane HC, Redfield RR. Covid-19 - Navigating the Uncharted. N Engl J Med. 2020;382(13):1268-1269. doi:10.1056/NEJMe2002387

23. MEDVESTNIK: Russian doctor portal. The chief cardiologist said a dramatic decrease in hospitalizations with a heart attack (Russian; author's translation) https://medvestnik.ru/content/news/Glavnyikardiolog-zayavil-o-dramaticheskom-snijenii- gospitalizacii-s-infarktom. html?utm_source=Итоговая+база_MB\&utm_campaign $=8 \mathrm{~b} 21 \mathrm{cb} 54 \mathrm{cb}$ letternews_2020.06.04\&utm_medium $=$ email\&utm_term=0_e42625fddb$8 b 21 \mathrm{cb} 54 \mathrm{cb}-55207803$ [Accessed on 03.06.2020]

24. De Rosa S, Spaccarotella C, Basso C, et al; Società Italiana di Cardiologia and the CCU Academy investigators group. Reduction of hospitalizations for myocardial infarction in Italy in the COVID-19 era. Eur Heart J. 2020 Jun 7;41(22):2083-2088. doi: 10.1093/eurheartj/ehaa409

25. European Society of Cardiology. STEMI admissions during COVID-19. An ESC survey on ST-elevation myocardial infarction (STEMI) admissions during the pandemic https://www.escardio.org/Education/COVID-19and-Cardiology/esc-survey-on-stemi-admissions-during-covid-19?utm medium=Email\&utm source=ESC\&utm_campaign=ESC+-+Newsletter++week+23+-+3+June [Accessed on 03.06.2020]

26. Gaisenok O.V., Alexandrova A.A., Savina N.M. Prevalence of obesity and its relationship with cardiovascular risk according to data of population screening programs. Social aspects of population health [serial online] 2020; 66(2):1. doi: 10.21045/2071-5021-2020-66-2-1.

27. Phung DT, Wang Z, Rutherford S, et al. Body mass index and risk of pneumonia: a systematic review and meta-analysis. Obes Rev. 2013 Oct;14(10):839-57. doi: 10.1111/obr.12055

28. Kassir R. Risk of COVID-19 for patients with obesity. Obes Rev. 2020 Jun;21(6):e13034. doi: 10.1111/obr.13034

29. Ashraf $S$, llyas $S$, Alraies MC. Acute coronary syndrome in the time of the COVID-19 pandemic. Eur Heart J. 2020 Jun 7;41(22):2089-2091. doi: 10.1093/eurheartj/ehaa454

30. World Health Organization. Italy. Statistics https://www.who.int/countries/ita/ en/ [Accessed on 03.06.2020]

31. The Demographic Yearbook of Russia 2019 https://gks.ru/bgd/regl/B19_16/ Main.htm [Accessed on 03.06.2020]

32. Shewan LG, Coats AJS, Henein MY. Authors' Responsibilities and Ethical Publishing. International Cardiovascular Forum Journal 2018;13:3-4 doi: 10.17987/icfj.v13i0.525 